\title{
Quadrature Sandwich Rectenna for Wireless Power Transfer
}

\author{
RACHED AGWIL, SERIOJA TATU \\ Dept. of ÉNERGIE MATÉRIAUX TÉLÉCOMMUNICATIONS RESEARCH CENTRE \\ Institut National de la Recherche Scientifique (INRS) \\ 800, De La Gauchetière Ouest Bureau 6900, Montreal \\ CANADA
}

\begin{abstract}
This novel work presents a quadrature sandwich rectenna circuit for collecting RF from four input ports at different angles. The scheme's high efficiency and increase in output power are significant for the operation of wireless electronic devices. This work demonstrates the requirements of self-powering. Specifically, simulation efficiency is shown to achieve $77 \%$, and input power is $0 \mathrm{dBm}$ for a $5 \mathrm{~K} \Omega$ resistance load and dual-band operation. The results of this experiment are encouraging in terms of wireless powering of some devices in wireless telecommunication systems. This scheme can also be applied to radio frequency wireless power transfer and harvesting, and would be useful in industrial, scientific, and medical applications. Furthermore, its mode of operation is sustainable, and it is compact.
\end{abstract}

Key-words: Wireless power transfer, energy harvesting, power combiner, printed circuits, rectifiers.

Received: May 30, 2020. Revised: October 8, 2020, Accepted: October 28, 2020. Published: November 17, 2020.

\section{Introduction}

Base transceiver stations (BTSs) and cellular towers are widely used to feed wireless devices and are parts of advanced telecommunication systems. Their function is to send and receive waves via radio frequency (RF) and microwave technology, as described in $[1,2]$. RF and microwave radiation are vital for transmitting information and energy to wireless devices, with BTSs keeping these devices continuously active.

Wireless receiver circuits have become widespread due to technological developments. These receiver circuits require continuous supplies of energy for sustained operation. Therefore, researchers have been working to produce solutions for the self-powering of wireless devices from RF signals. One of these solutions is energy harvesting $(\mathrm{EH})$, which is defined as a process of reaping alternating current $(\mathrm{AC})$ from external sources such as RF and converting it to direct current (DC).

Due to effective radiated power (ERP), approximately $50 \mathrm{dBm}$ per channel can be transmitted, as stated in $[1,2]$. This makes the conversion of RF to $\mathrm{EH}$ attractive due to its availability and cost-effectiveness. These aspects mean that it is practical for receiver circuit applications.

The study in [3] presented a receiver circuit that integrated an antenna and rectifier using a single diode. Its frequency of operation was from 2 to 18 $\mathrm{GHz}$ at an input power of between -17 and 15
$\mathrm{dBm}$. It obtained an efficiency of $20 \%$ with a resistance load of $100 \Omega$ at $3 \mathrm{GHz}$.

The experimental work in [4] designed a rectenna consisting of a slot-loaded dual-band folded dipole antenna and a dual-band rectifier. The resistance load was $2.2 \mathrm{k} \Omega$ and the input power was $-9 \mathrm{dBm}$. The authors [4] achieved measurement efficiencies of $37 \%$ and $30 \%$ at $915 \mathrm{MHz}$ and 2.45 $\mathrm{GHz}$, respectively.

In [5], a dual-frequency scheme was proposed with ultralow-power, using a single diode rectifier topology. The input power levels were -11 and $-13.5 \mathrm{dBm}$ at 915 and $2450 \mathrm{MHz}$, respectively. The output DC voltage was 200 and $313.5 \mathrm{mV}$, respectively, with a resistance load of $2200 \Omega$.

Another article presented a new rectenna topology to improve power handling [6]. It increased the number of rectifying branches with a single collected DC output, and the topology was tested using a two-branch rectifier. The power conversion efficiency was $57 \%$ at $17 \mathrm{dBm}$, for an operating frequency of $2.1 \mathrm{GHz}$.

The work in [7] demonstrated the concept of dual-band resistance compression networks (RCNs) for rectifier circuits with enhanced performance. Its proposed rectifier circuits changed the input power level and variations in the rectifier load. Further, the frequencies were a dual-band $915 \mathrm{MHz}$ and $2.45 \mathrm{GHz}$ rectifier based on an RCN. This reduced the sensitivity to variations in the output load and input power. 
In [8], a circuit receiver was designed for selfpower harvesting and wireless connection to an ambient base station. It attained efficiency of $54.81 \%$ at $0 \mathrm{dBm}$ input power. In other work, the researchers in [9] considered the time domain superposition coding technique, adding on the G3PLC standard and performing reproduction tests. Their outcomes show that the framework had a gain of up to $4 \mathrm{~dB}$ when the G3-PLC standard was added with time area superposition coding. However, the calculations could be challenged on the obstruction of high commotion and the adequacy of multipath impact.

A method was presented in [10] to reuse current for a wideband low noise amplifier (LNA) and ultra-wide band (UWB) purposes. It was completed by the wideband input matching and represents a collection of degenerative parallel LC circuit and resistive returns in a shunt-shunt connection. Additionally, the cascaded LC method was applied in [10] to obtain results matching.

The above-mentioned state-of-the-art approaches addressed some issues of converting RF to $\mathrm{DC}$ for $\mathrm{EH}$. However, there are several challenges involved in increasing DC output power. These problems are partly associated with combining RF with the rectifier's output power. Thus, the input power and the distance between the transmitter and receiver remain unresolved issues that affect the achieving of high power conversion efficiency (PCE).

In addressing this research gap, the present paper proposes a prototype to obtain proper results. The prototype achieves more bandwidth, higher efficiency and greater compactness, and is robustly packed in a box shape to protect its components from the elements.

The circuit in the proposed prototype consists of two layers in the form of a parallel $\mathrm{T}$-junction power combiner coupler for combining RF. Each T-junction power combiner coupler is connected to an L-type matching network. A pair rectifier voltage doubler is then used to combine separate DCs into a single output port. It is expressed as a quadrature input antenna RF energy reception angle side, with dual DC power. This is a multi-input, single-output (MISO) circuit that is shaped so that the elements are inside the box. The purpose is to combine RF reception, protect the elements, and combine DC outputs, as shown in Fig. 1.

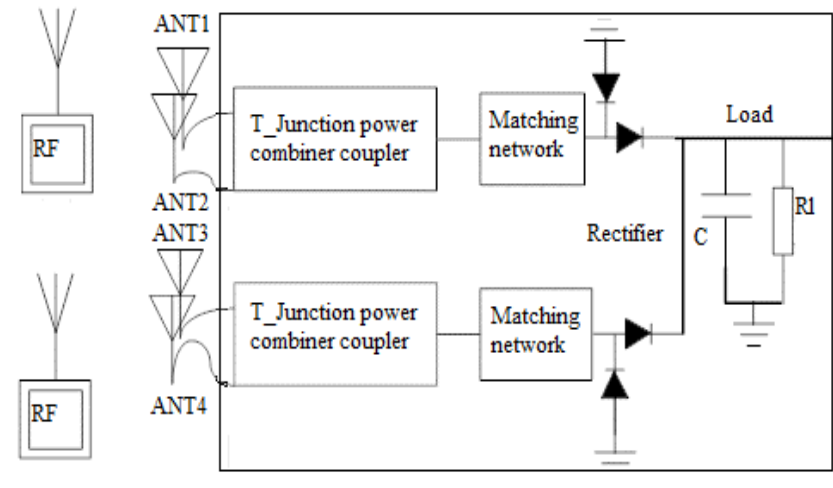

Fig. 1: System architecture, consisting of BTSs and the proposed circuit.

\section{Circuit Design and Simulation}

For the design, RO4350B laminate from Rogers Company was chosen, due to its low loss, availability, and low cost. Table 1 shows the parameters of the substrate. Several variables are used in the design of the circuit, including speed of light $c=3 \cdot 10^{8} \mathrm{~m} / \mathrm{s}$, frequency $f=5 \mathrm{GHz}$, and wavelength $\lambda=0.06 \mathrm{~m}$. Advanced Design System (ADS) software was used to design the circuit, and harmonic balance was used to simulate the analogue $\mathrm{RF}$ and microwave circuit for the prototype.

The parameters of the T-junction power combiner coupler are shown in Table 2. This scheme can be implemented using a transmission line (TL).

Table 1. Parameters of Substrate RO4350B [8]

\begin{tabular}{|l|c|c|c|}
\hline Relative & Thickness & Thickness & Loss \\
$(\mathcal{E} r)$ & $(h)$ & $\begin{array}{c}\text { of } \\
\text { copper } \\
\text { tangent }\end{array}$ & $($ TanD) \\
& & $1.5)$ & \\
\hline 3.48 & $1.52 \mathrm{~mm}$ & $17.5 \mu \mathrm{m}$ & 0.004 \\
\hline
\end{tabular}

Table 2. Component Parameters

\begin{tabular}{|l|l|}
\hline Characteristic impedance Z0 & $50 \Omega$ \\
\hline Z0 $\sqrt{2}$ & $70.7 \Omega$ \\
\hline TL width (W) of two input ports & $2 \mathrm{~mm}$ \\
\hline TL length (L) of two input ports & $3 \mathrm{~mm}$ \\
\hline TL W $=$ L of one output port & $3 \mathrm{~mm}$ \\
\hline Angle of each curve of TL & $90^{\circ}$ \\
\hline Curve W & $1.89 \mathrm{~mm}$ \\
\hline Curve L & $2 \mathrm{~mm}$ \\
\hline $\begin{array}{l}\text { TL to connect each curve with } \\
\text { input port or output port W }=\mathrm{L}\end{array}$ & $2 \mathrm{~mm}$ \\
\hline
\end{tabular}


Table 3 shows the parameters for a SPICE model pairs diode from a Skyworks Solutions datasheet.

Table 3. SPICE Model of SMS7630-006LF [11]

\begin{tabular}{|l|l|l|}
\hline Parameter & Unit & Value \\
\hline Is & A & $5 \mathrm{E}-6$ \\
\hline Rs & $\Omega$ & 20 \\
\hline N & - & 1.05 \\
\hline TT & Sec & $1 \mathrm{E}-11$ \\
\hline CJO & pF & 0.14 \\
\hline M & - & 0.40 \\
\hline EG & eV & 0.69 \\
\hline XTI & - & 2 \\
\hline FC & - & 0.5 \\
\hline BV & V & 2 \\
\hline IBV & A & $1 \mathrm{E}-4$ \\
\hline VJ & V & 0.34 \\
\hline
\end{tabular}

Figure 2 shows a schematic of the proposed system that consists of two layers of a T-junction power combiner coupler in parallel. Each T-junction is connected with a matching network and then connected with a voltage doubler integrated with the load stage.

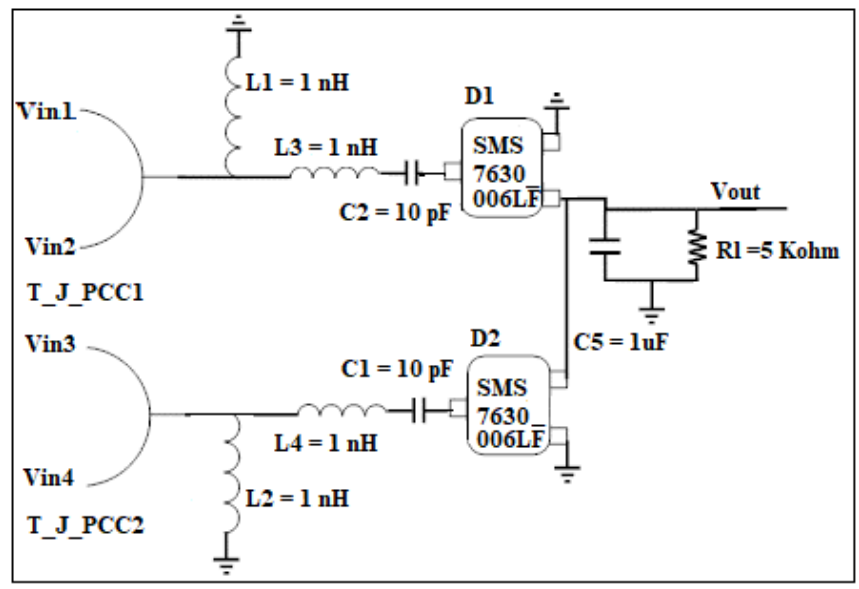

Fig. 2: Schematic of a two-layer T-junction power combiner coupler integrated dual voltage doubler.

Figure 3 shows the schematic of Schottky diode model SMS7630-006LF for the voltage doubler with the matching network. The output of the rectifier stage was combined with a capacitor to eliminate ripples in the load stage. This effectively increases the DC output power.

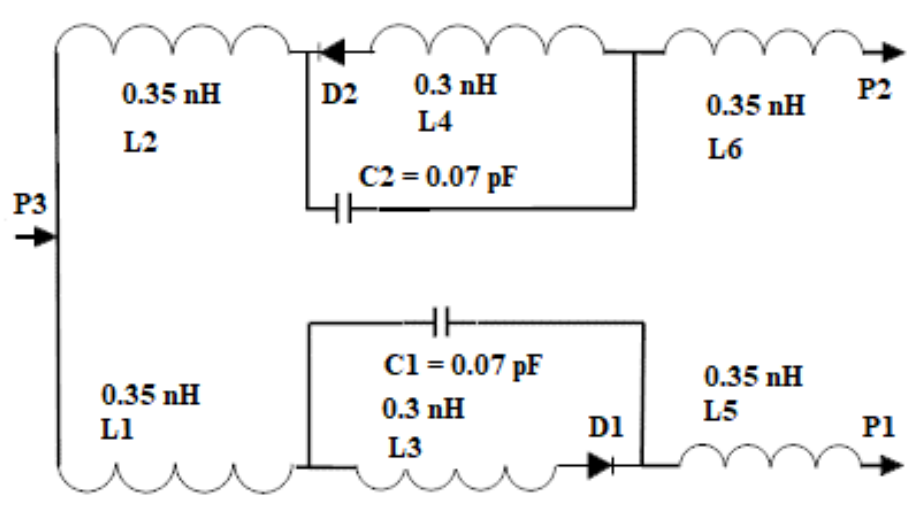

Fig. 3: Schematic of diode SMS7630-006LF.

Figure 4 plots the simulated DC output power $(\mathrm{dBm})$, as seen in Fig. 2. Four generators are connected to the receiver circuit in order to combine the DC outputs via a rectifier. A $0 \mathrm{~Hz}$ component shows output power of $-1.7 \mathrm{dBm}$, while all four generators combined show input power of $0 \mathrm{dBm}$, or $0.25 \mathrm{~mW}$ for each generator. The proposed structure is designed to reduce losses and has more electromagnetic waves captured by a two-dimension dual antenna. Using this design, the losses were reduced by $50 \%$ compared with our previous work [8]. Even when using an array of four antennas and a single detector, the simulation figured out more losses, with output power at $-6.6 \mathrm{dBm}$. These results were calculated using Equation (2.1), which expresses the output power as follows:

Output power $(\mathrm{dBm})=10 \log 10(0.5 \cdot$ real $($ Vout . I. load) +30

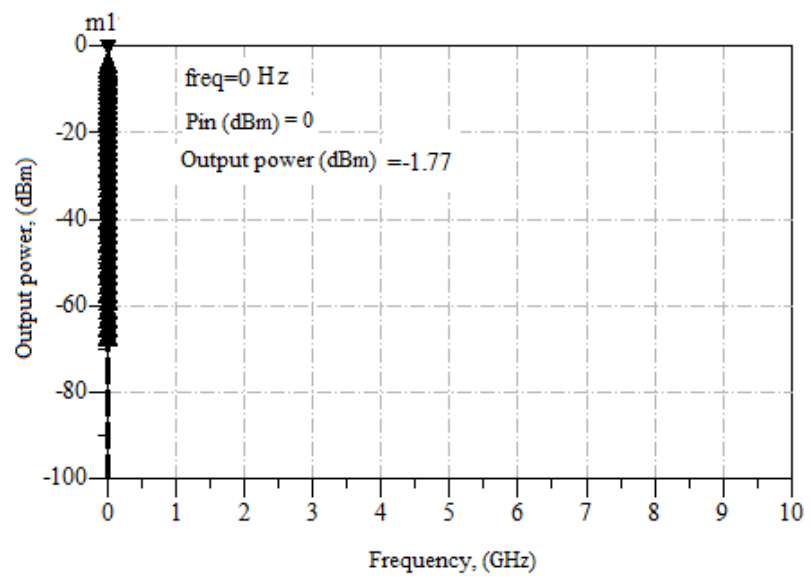

Fig. 4: DC output power (dBm) at $0 \mathrm{GHz}$. 
Figure 5 shows the circuit's efficiency in Fig. 2. As can be seen, four generators (Vin1, Vin2, Vin3, and Vin4) are connected, expressing multi-input and single Vout of output (MISO). Equation (2.2) was used to calculate the simulation of the efficiency. It achieved $10.4 \%, 39.7 \%, 63.9 \%$, and $77 \%$ for input power values of $-25,-15,-5$, and $0 \mathrm{dBm}$, respectively.

The efficiency is $(\eta)=$

$\frac{(\text { Pdc_Watt })}{\text { Input power } 1+\text { Input power } 2+\text { Input power } 3+\text { Input power } 4}$

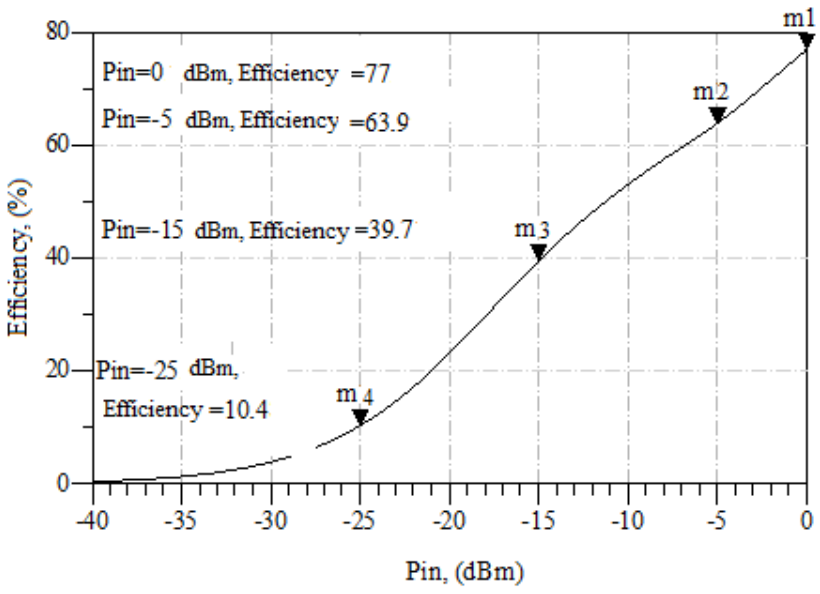

Fig. 5: Simulation efficiency of system.

Figure 6 shows values of $-20,-10$, and $0 \mathrm{dBm}$ for input power, giving outputs of $0.14,0.76$, and $2.57 \mathrm{~V}$, respectively. This result demonstrates the rectenna behaviour in terms of how the increase in input power affects output voltage.

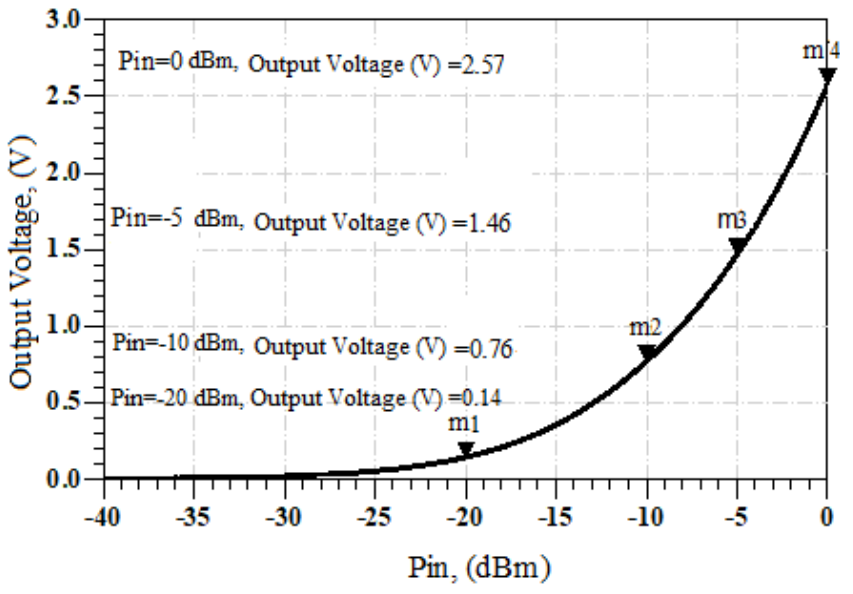

Fig. 6: Output voltage (V) versus input power $(\mathrm{dBm})$.

\section{Fabrication and Measurement}

This experiment involved the conversion of RF to DC from ambient RF sources. It used a T-junction power combiner coupler integrated with a parallel voltage doubler. Figure 7 shows a photo of the fabricated prototype with dimensions $(5 \times 3 \times 1) \mathrm{cm}$. It acts as a dual-voltage doubler for an RF-DC conversion circuit.

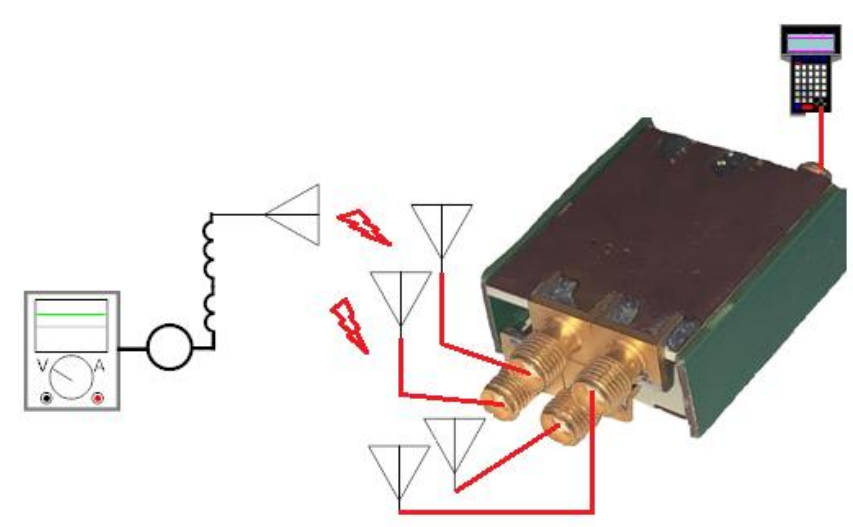

Fig. 7: Photo of fabricated circuit.

The measured setup indoors is depicted to show the path loss between the one transmission antenna (Tx) and the proposed circuit. It consists of four antenna receivers, as illustrated by far-field Equations (3.1) and (3.2), with the Friis equation in Equation (3.3). The measurement results for a power receiver are presented in Table 4.

For a far field of $2 \mathrm{GHz}$ :

$\mathrm{d} \geqq \frac{2 D^{2}}{\lambda}=\frac{2 \cdot 12^{2}}{15}=19.2 \mathrm{~cm}$

For a far field of $6 \mathrm{GHz}$ :

$\mathrm{d} \geqq \frac{2 D^{2}}{\lambda}=\frac{2 \cdot 12^{2}}{5}=57.6 \mathrm{~cm}$

$\mathrm{P}_{\mathrm{rx}}=\mathrm{P}_{\mathrm{tx}}+\mathrm{G}_{\mathrm{tx}}+\mathrm{G}_{\mathrm{rx}}+20 \cdot \log _{10}\left(\frac{\lambda}{4 d}\right)$

In a case where $\lambda=0.15 \mathrm{~m}$,

$$
=-5+6+15+(-24.12)=-8.12 \mathrm{dBm} \text {. }
$$

In a case where $\lambda=0.05 \mathrm{~m}$,

$$
=-5+6+15+(-43.21)=-27.21 \mathrm{dBm} .
$$


Table 4. Measurements of Output Power

\begin{tabular}{|l|l|l|l|}
\hline \multicolumn{5}{|c|}{$\begin{array}{l}\text { Input power } \mathrm{P}_{\text {in }}=-5 \mathrm{dBm} \text { and } \\
\text { distance } \mathrm{d}=1 \mathrm{~m}\end{array}$} \\
\hline $\begin{array}{l}\mathrm{f} \\
(\mathrm{MHz})\end{array}$ & $\begin{array}{l}\text { Output power } \\
(\mu \mathrm{W})\end{array}$ & $\begin{array}{l}\mathrm{f} \\
(\mathrm{MHz})\end{array}$ & $\begin{array}{l}\text { Output } \\
\text { power } \\
(\mu \mathrm{W})\end{array}$ \\
\hline 1650 & 10 & 6550 & 10 \\
\hline 1700 & 8 & 6600 & 1 \\
\hline 1750 & 3 & 6650 & 6 \\
\hline 1800 & 6 & 6700 & 10 \\
\hline 1850 & 6 & 6750 & 3 \\
\hline 1900 & 10 & 6800 & 3 \\
\hline 1950 & 10 & 6850 & 5 \\
\hline 2000 & 32 & 6900 & 5 \\
\hline 2050 & 10 & 6950 & 8 \\
\hline 2100 & 3 & 7000 & 13 \\
\hline
\end{tabular}

The cellular base transceivers in [1], for both urban and suburban areas, presented effective radiation power (ERP), transmitting around $50 \mathrm{dBm}$ for wireless electronic devices, which can cover a longer distance. In the lab, indoor radiation power of $\mathrm{Ptx}=-5 \mathrm{dBm}$ is used. In the shorter range of $1 \mathrm{~m}$, the proposed system can be employed when Gtx $=6 \mathrm{~dB}$ and Grx $=9 \mathrm{~dB}$. The system is able to operate from 0.5 to $2.5 \mathrm{~V}$, with an initial input sensitivity of $-13 \mathrm{dBm}$. The proposed circuit depends on the voltage consumer required of the device application. The Friis equation in (3.3) is applied to find the proposed receiver circuit's output power. In this case, we take $\lambda=$ $0.15 \mathrm{~m}$ and use a distance $\mathrm{d}$ of $500 \mathrm{~m}$ :

$$
\mathrm{P}_{\mathrm{rx}}=50+15+6+(-92.44)=-21.44 \mathrm{dBm} .
$$

The distance $\mathrm{d}$ is $250 \mathrm{~m}$ when $\lambda=0.15 \mathrm{~m}$.

$$
\mathrm{P}_{\mathrm{rx}}=50+15+6+(-86.42)=-15.42 \mathrm{dBm} .
$$

The limitations of a rectifier are required to perform the output DC voltage for WPT [6]. These limitations and assumptions depend on the output voltage, as seen in Fig. 6. When the target is $1.5 \mathrm{~V}$, it needs input power -7 $\mathrm{dBm}$, which can be applied to powering sensors. Therefore, the circuit can be very useful for WPT. For power harvesting, the distance must be calculated by the Friis equation for power receiver.

Table 5 shows a comparison between this work and some of the previous research mentioned in the Introduction section. The targeted parameters are related to wireless power transfer in ISM applications [12-13]. A broad-band rectenna $1^{\times 4}$ quasi-Yagi antenna array is formed with a T-junction power divider for GSM-1800 and UMTS-2100 bands in [14].
It obtained $40 \%$ PCE, $224 \mathrm{mV}$ output DC voltage at $5 \mathrm{k} \Omega$ resistor, with input power of $-3.4 \mathrm{dBm}$. In [15], a dual-band rectenna array was fabricated using a power combiner in two pairs for powering an IoT application sensor. It operates at frequencies of $895-925 \mathrm{MHz}$ and 1.6-2.65 GHz. The resistor load is $2200 \Omega$ and input power is -10 $\mathrm{dBm}$. The efficiency obtained is $55 \%$ for the GSM900, 41.5\% for the DCS1800, and 33\% for the WiFi bands. Energy harvesting can be used to power sensor nodes in many applications, such as healthcare monitoring, environment monitoring, and structural monitoring [16].

Table 5. Comparison Between This Work and

\begin{tabular}{|c|c|c|c|c|c|}
\hline Ref. & $\begin{array}{l}\text { Freq } \\
(\mathrm{MHz})\end{array}$ & $\begin{array}{l}\text { Input } \\
\text { power } \\
\text { Pin } \\
(\mathrm{dBm})\end{array}$ & $\begin{array}{l}\text { Efficiency } \\
\eta(\%)\end{array}$ & $\begin{array}{l}\text { Rload } \\
(\Omega)\end{array}$ & $\begin{array}{l}\text { Size } \\
(\mathrm{mm})\end{array}$ \\
\hline [4] & $\begin{array}{l}915 \\
2450\end{array}$ & -9 & $\begin{array}{c}37 \\
30\end{array}$ & 2200 & $\begin{array}{l}60^{x} \\
60^{x}\end{array}$ \\
\hline [5] & $\begin{array}{l}915 \\
2450\end{array}$ & $\begin{array}{l}-13.5 \\
-11\end{array}$ & $\begin{array}{l}40.7 \\
56.2\end{array}$ & 2200 & $\begin{array}{l}61.5^{\times} \\
44.46\end{array}$ \\
\hline [6] & $\begin{array}{l}2110 \\
\text { to } \\
2170 \\
\end{array}$ & 17 & $57 \%$ & 300 & $\begin{array}{l}70^{\times} \\
50\end{array}$ \\
\hline $\begin{array}{l}\text { This } \\
\text { work }\end{array}$ & $\begin{array}{l}1650 \\
\text { to } \\
2100 \\
\& \\
6550 \\
\text { To } \\
7000\end{array}$ & $\begin{array}{l}0 \\
-15\end{array}$ & $\begin{array}{l}77 \\
39.7\end{array}$ & 5000 & $\begin{array}{l}50^{\times} \\
30^{\times} 10\end{array}$ \\
\hline
\end{tabular}
Other Reported Work

\section{Conclusion}

This work presented an enhanced structural implementation that operates using two opposing layers and with fewer components. It combines double dual input RF in multi-dimensions and accumulates through the rectifier output. The rectifier was verified to cover most ISM frequency bands, especially for WPT. The PCE achieved $77 \%$ efficiency at $0 \mathrm{dBm}$ input power level with low loss of DC output power, which is essential for self-powering of wireless electronic devices.

As the circuit facility demonstrates, our design for the output voltage obtained $2.57 \mathrm{~V}$ of RF to DC for WPT, giving it confirmable uses in telecommunication systems such as RFID and IoT sensor applications. Further, the design's 
effectiveness makes it a prospective candidate for facilitating self-sustainability in communication systems, mainly as part of the green communication business.

Overall, in comparison with the previous research endeavours mentioned earlier in the paper, this work has improved several parameters such as efficiency, broadband, and robustness. Moreover, the circuit is compact in a box, offering protection to the components from environmental impacts, and is low-cost, lightweight, and small in size.

Future work will focus on improving multirectifier combinations to increase output power.

\section{References:}

[1] Human Exposure to Radio Frequency Fields: Guidelines for Cellular Antenna Sites.

[2] Y. Luo, et al., "RF Energy Harvesting Wireless Communications: RF Environment, Device Hardware and Practical Issues," Sensors, vol. 19, no. 13, pp. 1-28, 2019.

[3] J. A. Hangerty, F.B. Helmberecht., W. H. Mccalpin, R. Zane, Z. B. Popovic, Recycling ambient microwave energy with broad-band rectenna arrays, Vol. 52, No. 3, p. 1014-1024, DOI: 10.1109/TMTT.2004.823585, 2004.

[4] K. Niotaki., et al. A compact dual-band rectenna using slot-loaded dual band folded dipole antenna. IEEE Antennas and Wireless Propagation Letters.;12:1634-1637, 2013.

[5] Scheeler, R., Korhummel, S., Popovic, Z. A dual-frequency ultralow-power efficient $0.5-\mathrm{g}$ rectenna, IEEE Microwave Magazine, , vol. 15, no. $1, \quad$ p. $109-114,2014$ DOI: 0.1109/MMM.2013.2288836.

[6] M. Abdallah, J. Costantine, A. H. Ramadan and Y. Tawk, "A Rectenna System With Power Combining Topology for Improved Power Handling Capabilities," in IEEE Sensors Letters, vol. 2, no. 4, pp. 1-4, Art no. 1501304, doi: 10.1109/LSENS.2018.2868825, Dec. 2018.

[7] K. Niotaki, A. Georgiadis, A. Collado and J. S. Vardakas, "Dual-Band Resistance Compression Networks for Improved Rectifier Performance," in IEEE Transactions on Microwave Theory and Techniques, vol. 62, no. 12, pp. 3512-3521, doi: 10.1109/TMTT.2014.2364830, Dec. 2014.

[8] R.O. Agwil, S.O. Tatu, Combine RF Ambient for Power Harvesting Using Power Detector for Sensor Application over L, S, C Bands. International Research Journal of Engineering and Technology (IRJET), Vol. 07, no. 01, Jan. 2020.

[9] Li Zhao, Xiaolu Jiao, Tong Zhu, and Feng Zhang, Anti-noise Algorithm Based on Time Domain Superposition in G3-PLC System, International Journal of Circuits, Systems and Signal Processing, pp. 328-335, Volume 13, 2019.

[10] M.S. Kusuma, S. Shanthala, Cyril Prasanna Raj P., Design of 3.1-10.6 GHz CMOS UWB LNA Using Current Reuse Technique, International Journal of Circuits, Systems and Signal Processing, pp. 472-476, Volume 13, 2019.

[11] Data Sheet, Surface-Mount Mixer and Detector Schottky Diodes, Skyworks Solutions, Inc, June 1, 2018. https://id.ic-

components.com/files/1e/SMS7621-005LF.pdf. [12] L. Xie, Y. Shi, Y. T. Hou and A. Lou, "Wireless power transfer and applications to sensor networks," in IEEE Wireless Communications, vol. 20, no. 4, pp. 140-145, August 2013, doi: 10.1109/MWC.2013.6590061. [13] Y. Peng, Z. Li, W. Zhang and D. Qiao, "Prolonging Sensor Network Lifetime Through Wireless Charging," 2010 31st IEEE Real-Time Systems Symposium, San Diego, CA, 2010, pp. 129-139, doi: 10.1109/RTSS.2010.35.

[14] H. Sun, Y. Guo, M. He and Z. Zhong, "A Dual-Band Rectenna Using Broadband Yagi Antenna Array for Ambient RF Power Harvesting," in IEEE Antennas and Wireless Propagation Letters, vol. 12, pp. 918-921, 2013, doi: 10.1109/LAWP.2013.2272873.

[15] H. He and T. Li, "Design of an indoor RF Energy Harvesting Module using Dual-Band Rectenna Array for IoT Applications," 2019 IEEE 4th Advanced Information Technology, Electronic and Automation Control Conference (IAEAC), Chengdu, China, 2019, pp. 1407-1410,doi: 10.1109/IAEAC47372.2019.8998043.

[16] S. Sudevalayam and P. Kulkarni, "Energy Harvesting Sensor Nodes: Survey and Implications," in IEEE Communications Surveys \& Tutorials, vol. 13, no. 3, pp. 443-461, Third Quarter 2011, doi: 10.1109/SURV.2011.060710.00094.

\section{Creative Commons Attribution License 4.0 (Attribution 4.0 International, CC BY 4.0)}

This article is published under the terms of the Creative Commons Attribution License 4.0 https://creativecommons.org/licenses/by/4.0/deed.en_US 